\title{
COMPARATIVE STUDY BETWEEN LASER SINTERED IMPLANT AND ACID ETCHED IMPLANT SEATED IN THE MAXILLARY PREMOLAR AREA
}

\author{
Halwag $\mathrm{A}^{1} B D S$, El Prince $\mathrm{N}^{2} P h D$, Eldibany $\mathbf{R}^{2} P h D$.
}

\begin{abstract}
:
Introduction: conventionally dental implants were produced by machining titanium rods, then surface treatments or coatings are applied. The direct laser fabrication (DLF) is a new technology by which we can produce a dental implant with complex geometry that allows better osseointegration, through enhancing the differentiation of stem cells into osteoblasts and endotheliocytes leading to bone formation around the implant in a better and quicker way.

Objectives: to compare osseointegration between laser sintered implants and acid etched implants.

Materials and methods: This randomized clinical trial was conducted on twenty patients having edentulous spaces in the maxillary premolar area. They were divided equally into two groups, group A and group B, ten patients in each group. Laser sintered implants were placed in the edentulous spaces in group A patients, while conventional implants were placed in group B patients. Clinical and radiographic evaluations were carried out after 4, 6 and 9 months for both groups.

Results: : Regarding the plaque index the scores of group A were found to be insignificantly lower than those of group B at 4 and 6 months and significantly lower at 9 months. The mean probing depth values in group A were significantly lower than group B at 4 and 6 months and insignificantly lower at 9 months. While, the implant mobility score was 0 for both groups. Regarding the mean marginal bone defect, values for group A were insignificantly lower than group B at 4 months, while significantly lower at 6 and 9 months.
\end{abstract}

Conclusion: The use of both laser sintered and acid etched implants for replacement of maxillary premolars have significant success.

Key words: Laser sintered, Acid etched, Dental implants, Osseointegration.

1. B.D.S. Faculty of Dentistry, Alexandria University.

2. Professor of Oral and Maxillofacial Surgery, Faculty of Dentistry, Alexandria University.

\section{INTRODUCTION}

Nowadays, dental implants are fabricated by machining titanium rods, followed by modification of the implant surface design, such as sandblasting, acid-etching, anodization, discrete calcium-phosphate crystal deposition, and chemical modification. These have all been used to improve stability and enhance osseointegration (1-7).

In fact, several studies have demonstrated that implant surface topography plays a pivotal role in many periimplant cellular and molecular mechanisms (1-8). Rough surfaces have demonstrated better adsorption of biomolecules from biological fluids, which has the potential to alter the cascade of events that leads to bone healing and intimate apposition with the implant $(1,8)$. In vitro reports indicate that rough surfaces improve the initial cellular response, including cytoskeletal organization and cellular differentiation with matrix deposition $(1,86,7)$. Histologically, it has been demonstrated that rough surfaces can effectively promote better and faster osseointegration, when compared to machined surfaces $(9,10)$. From a clinical point of view, several studies have reported excellent long-term survival/ success rates for rough surface implants $(3,5,11)$.

Direct metal laser sintering (DMLS) is a laser-based additive manufacturing technique, in which an object is built layer by layer using powdered metals, radiant heaters, and a computer-controlled laser. Basically, the machine produces the object on a moveable platform by applying incremental layers of the pattern material. For each layer, the machine lays down a film of powders, with an accurate thickness $(0.1 \mathrm{~mm})$. Then, a high power laser beam is directed on a powder bed and programmed to fuse metal powders present in its focal zone, according to a computerassisted-design (CAD) file, thus generating a thin metal layer. The platform moves down the preprogrammed layer thickness, a fresh film of powder is laid down, and the next layer is melted with exposure to the laser source, so that it conforms to the previous layer. This process continues, layer by layer, until the object is fabricated (12-16).

With DMLS it is possible to control the porosity of each layer but also pore interconnectivity, size, shape, and distribution, and consequently the $3 \mathrm{D}$ architecture of the implant, by changing the processing parameters, such as laser power and peak power (for continuous wave and pulsed lasers, resp.), laser spot diameter, layer thickness, hatching pitch (or scan spacing), scan speed, and scanning strategy, or by modifying the size of the original titanium particles. This is an important advantage of this technique: a high level of interconnectivity resulting in a predominantly open pored morphology may allow bone ingrowth and vascularization, thus enhancing osseointegration, the essential factor of the long-term reliability of an implant (12-16).

In addition, since the mechanical properties of biomaterials are dependent on their microarchitecture, DMLS technology can be used to fabricate porous titanium implants with mechanical properties close to bone. In fact, a porous implant will have a yield strength and elastic modulus that are reduced compared to a fully dense component. As a result, the mechanical properties of a 
porous device can be tailored to better match the yield strength and elastic modulus of the host bone and therefore avoid undesired effects such as "stress shielding" which is associated with a mismatch in bone-implant elastic moduli (12-16).

In the light of the above information, this study was designed to compare the DMLS implants with the standard acid etched implants.

\section{MATERIALS AND METHODS}

This randomized clinical trial was conducted on twenty patients having edentulous spaces in the maxillary premolar area and indicated for implant insertion, they were of both sexes, their age ranged between 27-35 years. They were selected from the Outpatient Clinic of the Department of Oral and Maxillofacial Surgery, Faculty of Dentistry, Alexandria University.

These patients were randomly assigned to one of two groups (group A or group B); ten patients were allocated in each group, patients in group A received laser sintered implants, Tixos (Leader, Cinisello Balsamo, Milan, Italy) while those in group B received conventional acid etched implants, Implus (Leader, Cinisello Balsamo, Milan, Italy).

The inclusion criteria of this study were; patients having one or more maxillary premolar tooth extracted at least 3 months prior to implant insertion, and patients having adequate bone to allow placement of implants of at least 7 $\mathrm{mm}$ length and $3.3-5 \mathrm{~mm}$ width. While the exclusion criteria were medical contraindications for implant surgery, smoking, parafunctional habits and patients having any pathological condition in the extraction site.

Patients were fully informed about the treatment procedures and follow up examination. Appropriate institutional ethical clearance and written informed consent were obtained.

\section{Materials}

Tixos implants (Leader, Cinisello Balsamo, Milan, Italy) have micro fused, porous, with isoelastic surface and selfthreading grade $\mathrm{V}$ titanium fixture, sterilized by gamma rays $25 \mathrm{kgy}$, double packed in airtight sealed glass vial and blister. Fixture lengths: $(10,11.5,13 \mathrm{~mm})$, fixture diameter: $(3.75,4.5 \mathrm{~mm})$, fixture platform: $4.75 \mathrm{~mm}$. (Fig. 1a).

Implus implants (Leader, Cinisello Balsamo, Milan, Italy) have micro roughened surface, self-threading grade IV titanium fixture, have three anti-rotational threads in the apical portion, sterilized by gamma rays $25 \mathrm{kGy}$, double packed in airtight sealed glass vial and blister. Fixture lengths: $(9,11,13 \mathrm{~mm})$, Fixture diameter. $3.75,4.5 \mathrm{~mm}$, Fixture platform: $4.75 \mathrm{~mm}$. (Fig. 1b).

\section{Pre-operative procedures.}

- Clinical assessment of patient's general health, oral condition, evaluation of the implant site by inspection and palpation of the surrounding oral mucosa, occlusion and adjacent teeth.

- Radiographic evaluation included: a) Standardized periapical radiographs using X.C.P. (Extension Cone Paralleling) (Rinn Co. Dentsply Division, USA).

b) Orthopantomogram (OPG). (Fig. 2a).

- A surgical stent was prepared on mounted models to serve as a guide to implant osteotomy.

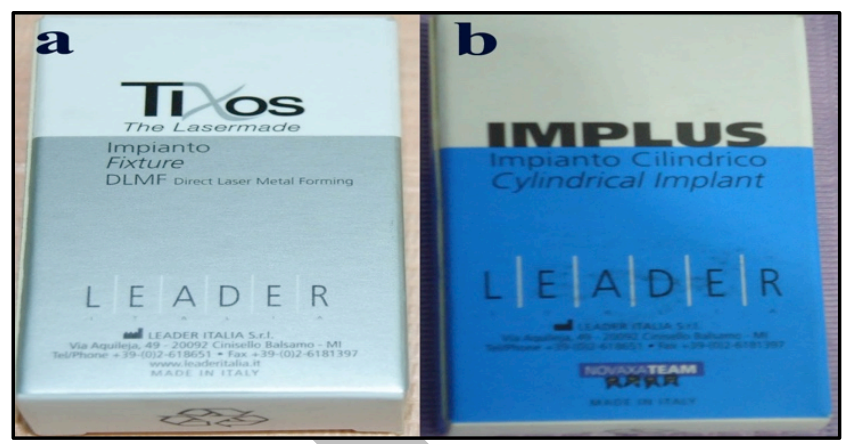

Fig. 1: A photograph showing (a) Leader-tixos implant. (b) Leader-implus implant.

\section{Surgical procedure}

All the surgeries were performed in the dental clinic in the Department of Oral and Maxillofacial Surgery, Faculty of dentistry, Alexandria University.

Chlorhexidine $0.12 \%$ (Hexitol mouth wash, Arab drug company, Cairo, Egypt) was used to rinse the oral cavity for one minute before surgery. The local anesthesia, lidocaine $2 \%$ with epinephrine, (Lignospan 2\%, Septodont, Saint-Maur-des-fossésCedex, France) was administered with local infiltration into the surgical area.

A full-thickness mucoperiostal flap (with vertical releasing incisions close to gingival papillae) was raised to expose the surgical site. (Fig. 2b) Using the surgical stent and the standard leader-tixos surgical kit, a medium-sized round drill was selected (the guide drill), and the sites of implant insertion was marked with it then a twist drill was used to drill the primary osteotomy.

After removing the surgical stents, a series of drills were used to enlarge the osteotomy site according to the implant size. (Fig. 2c) A counter sink was prepared using its special drill. The implant leader-tixos for the group A and leaderimplus for the group B was tightened by fingers then by ratchet wrench till the bone level. The cover screw was placed (Fig. 2d), and then the flap was repositioned and sutured using $(3 / 0)$ black silk suture.

\section{Post-surgical care}

After the surgery, the patients were instructed to apply cold compresses on the surgical sites; and not to brush or irritate it for 10 days, to rinse their mouth with chlorhexidine $0.12 \%$ (Hexitol mouth wash, Arab drug company, Cairo, Egypt) three times a day for 1 week, and to maintain a soft diet for about 6 weeks. Analgesics, diclofenac potassium 50mg, (cataflam $50 \mathrm{mg}$ tablet, Novartis Pharma, Cairo, Egypt) three times daily and antibiotic, amoxicillinclavulanic acid 1g, (Augmentin 1g , GlaxoSmithKline. Cairo, Egypt) twice daily were prescribed for seven post- 
operative days. The sutures were removed seven days after implant insertion.

\section{Prosthetic phase}

After four months the cover screw was removed and the abutment was tightened, and porcelain fused to metal crown was placed.

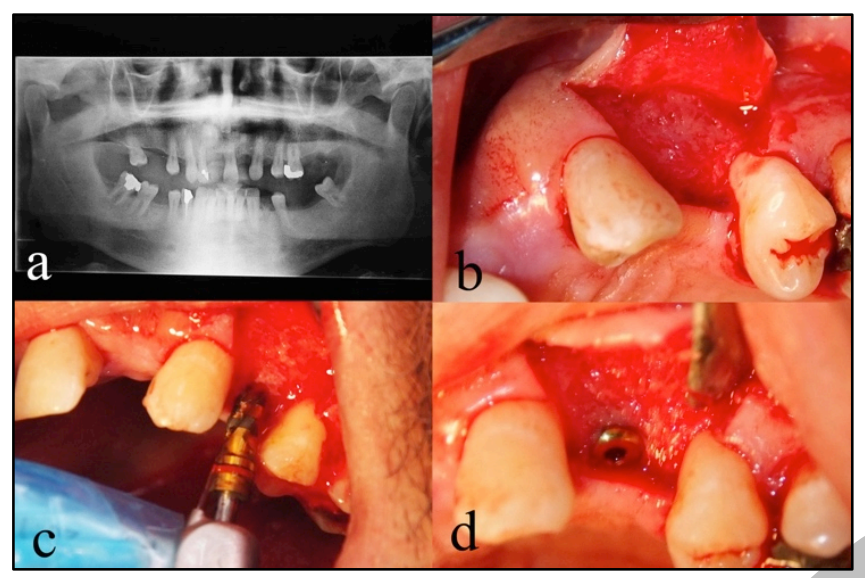

Fig. 2: (a) Preoperative panorama showing missing maxillary left first premolar. (b) A photograph showing mucoperiostal flap elevation. (c) A photograph showing the drilling of implant socket. (d) A photograph showing the tightened cover screw.

\section{Clinical Evaluation}

All patients were examined at the intervals of four, six and nine months to check for the presence of pain, discomfort, swelling, or infection. Then, the following clinical parameters were used to clinically evaluate the cases at the same intervals.

The probing pocket depth was measured according to Glavin and Loe (17), Plaque index was measured according to Silness and Loe (18), and Implant mobility was assessed manually; according to criteria developed by McKinney \&Koth (19).

\section{Radiographic Evaluation}

Standardized peri-apical radiographs were taken preoperatively and after 4, 6 and 9 months to evaluate changes of marginal bone level around the dental implant. (Fig. 3a3d). The radiographs were scanned and the marginal bone loss was measured using Image J software (Image J, U. S. National Institutes of Health, Bethesda, Maryland, USA).

\section{Statistical analysis}

The results of all examinations were registered on a case record form and were entered into an electronic database to be analyzed statistically. The distributions of data were tested for normality. Also, comparison between the two group at each period were done using independent t-test, while, comparison between two periods in each group was done using ANOVA test. $\mathrm{P}$ value $\leq 0.05$ was considered statistically significant.

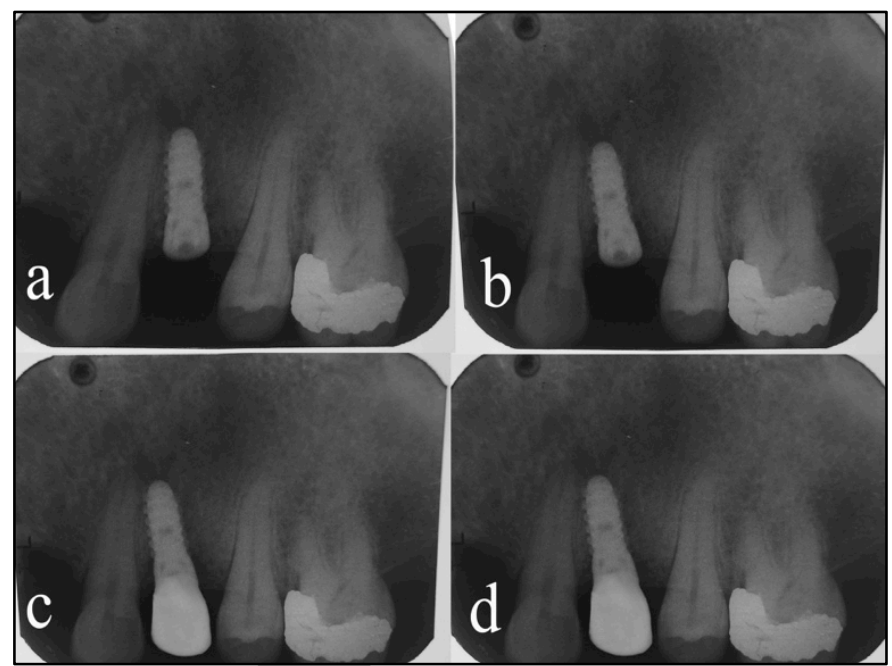

Fig. 3: Postoperative periapical radiograph showing (a) immediate placement. (b) After 4 months. (c) After 6 months. (d) After 9 months.

\section{RESULTS}

In this study twenty implants were placed in a total of twenty patients ( 13 females and 7 males) having missing maxillary premolars. Their ages ranged between 27 and 35 years with mean age of 30 years. They were selected from the Outpatient Clinic of the Oral and Maxillofacial Surgery Department, Faculty of Dentistry, Alexandria University. All patients had undergone surgical procedures for delayed implant placement and loading. All patients were followed up both clinically and radiographically for 9 months.

All patients had been operated under local anesthesia using surgical flap technique and implant placement, and no complications had been recorded during the operation.

All patients had been examined periodically during the follow-up period up to 9 months. Healing was uneventful in all cases with no post-operative complications.

\section{I- Clinical evaluation}

- Pain, tenderness, infection or swelling

There was absence of pain and tenderness after one week and during the follow up period. Postoperative edema and discomfort were very minimal and unobserved, with no post-operative swelling or infection.

- Plaque index: Mean Plaque index values and standard deviation for both groups were measured at 4, 6 and 9 months. They were $(0.80 \pm 0.11,0.80 \pm 0.11$ and $0.68 \pm$ $0.12)$ respectively for group $A$ and $(0.90 \pm 0.13,0.85 \pm 0.13$ and $0.80 \pm 0.11$ ) respectively for group $\mathrm{B}$. The difference in Plaque index values was found to be statistically insignificant at 4 and 6 months and significant at 9 months $(\mathrm{p}=0.074, \mathrm{p}=0.355, \mathrm{p}=0.024)$ respectively.

- Probing pocket depth: Mean probing depth values and standard deviation for both groups were measured at 4, 6 and 9 months. They were $(1.78 \pm 0.33,2.29 \pm 0.33$ and 2.59 $\pm 0.32)$ respectively for group $\mathrm{A}$ and $(2.51 \pm 0.33,2.71 \pm$ 0.35 and $2.78 \pm 0.24$ ) respectively for group B. The difference in probing depth values was found to be statistically significant at 4 and 6 months and insignificant 
at 9 months $(\mathrm{p}<0.001, \mathrm{p}=0.012, \mathrm{p}=0.163)$ respectively. (Fig. 4) (Table 1).

- Implant Mobility: none of the implants of both groups showed signs of mobility throughout the evaluation period (i.e. mobility score 0 ).

\section{II- Radiographic evaluation}

Mean marginal bone defect values and standard deviation for both groups were measured at 4, 6 and 9 months. They were $(1.34 \pm 0.11,1.71 \pm 0.03$ and $1.98 \pm 0.05)$ respectively for group $\mathrm{A}$ and $(1.35 \pm 0.09,1.82 \pm 0.07$ and $2.05 \pm 0.06)$ respectively for group $\mathrm{B}$. The difference in marginal bone defect values was found to be statistically insignificant at 4 months and significant at 6 and 9 months $(p=0.827$, $\mathrm{p}<0.001, \mathrm{p}=0.004$ ) respectively. (Fig. 5) (Table 2).

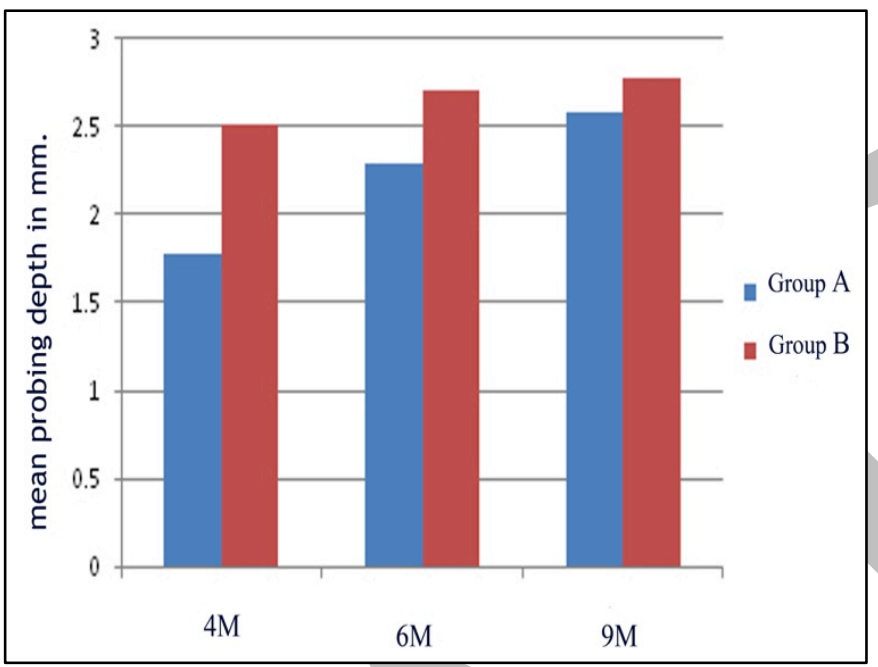

Fig. 4: Comparison between the two groups according to the probing depth.

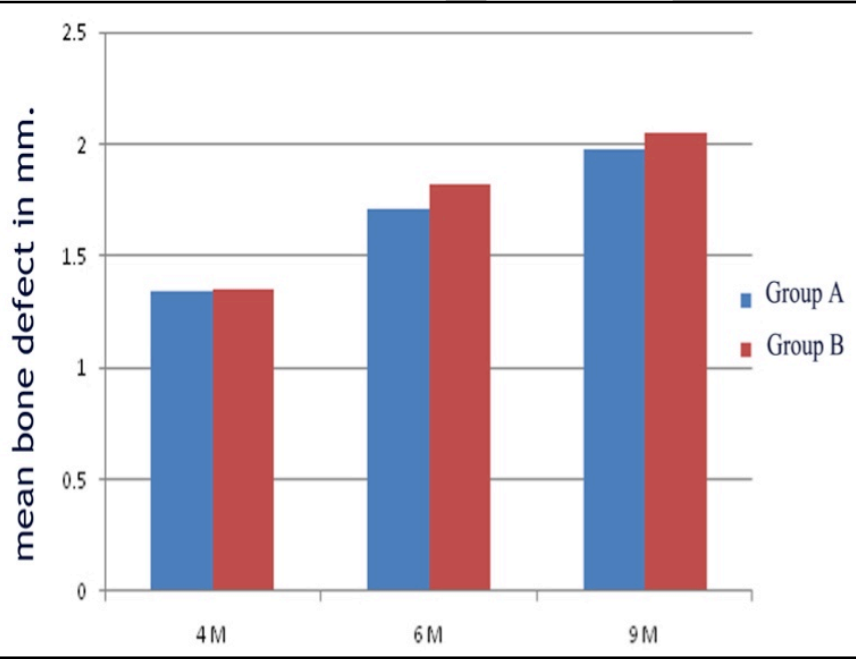

Fig. 5: Comparison between the two groups according to the marginal bone defect.
Table 1: Comparison between two studied groups according to peri-implant probing depth at each period.

\begin{tabular}{|c|c|c|c|}
\hline & \multicolumn{3}{|c|}{ Pro Depth } \\
\hline & After 4 mon ths & After 6 months & After 9 months \\
\hline \multicolumn{4}{|l|}{ Group A } \\
\hline Min. -Max. & $1.50-2.50$ & $2.0-3.0$ & $2.0-3.0$ \\
\hline Mean \pm SD & $1.78 \pm 0.33$ & $2.29 \pm 0.33$ & $2.59 \pm 0.32$ \\
\hline Median & 1.50 & 2.50 & 2.50 \\
\hline p & & $<0.001^{\circ}$ & $<0.001^{*}$ \\
\hline \multicolumn{4}{|l|}{ Group B } \\
\hline Min. -Max. & $2.0-3.0$ & $2.0-3.0$ & $2.50-3.0$ \\
\hline Mean \pm SD & $2.51 \pm 0.33$ & $2.71 \pm 0.35$ & $2.78 \pm 0.24$ \\
\hline Median & 2.50 & 2.50 & 2.50 \\
\hline $\mathrm{p}$ & & $0.008^{\circ}$ & $<0.001^{*}$ \\
\hline$t$ & $4.940^{\circ}$ & $2.784^{\circ}$ & 1.455 \\
\hline p & $<0.001^{\circ}$ & $0.012^{*}$ & 0.163 \\
\hline
\end{tabular}

Table 2: Comparison between two studied groups according to bone defect at each period.

\begin{tabular}{|c|c|c|c|}
\hline & \multicolumn{3}{|c|}{ Marginal Bone $D$ efect } \\
\hline & $\begin{array}{l}\text { After } 4 \\
\text { months }\end{array}$ & $\begin{array}{l}\text { After } 6 \\
\text { months }\end{array}$ & $\begin{array}{l}\text { After } 9 \\
\text { mon ths }\end{array}$ \\
\hline \multicolumn{4}{|l|}{ Group A } \\
\hline Min - Max. & $1.20-1.50$ & $1.66-1.75$ & $1.86-2.05$ \\
\hline Mean \pm SD & $1.34 \pm 0.11$ & $1.71 \pm 0.03$ & $1.98 \pm 0.05$ \\
\hline Median & 1.31 & 1.71 & 1.98 \\
\hline $\mathbf{p}_{1}$ & $<0.001^{*}$ & $<0.001^{*}$ & $<0.001^{*}$ \\
\hline \multicolumn{4}{|l|}{ Group B } \\
\hline Min. - Max. & $1.20-1.50$ & $1.75-1.90$ & $1.98-2.20$ \\
\hline Mean \pm SD & $1.35 \pm 0.09$ & $1.82 \pm 0.07$ & $2.05 \pm 0.06$ \\
\hline Median & 1.35 & 1.84 & 2.05 \\
\hline $\mathbf{p}_{1}$ & $<0.001^{*}$ & $<0.001^{\circ}$ & $<0.001^{\circ}$ \\
\hline $\mathbf{t}$ & 0.222 & $5.006^{\circ}$ & $3.320^{\circ}$ \\
\hline $\mathbf{p}$ & 0.827 & $<0.001^{\circ}$ & $0.004^{*}$ \\
\hline
\end{tabular}

( t: student t-test, p1: Adjusted Bonferroni p-value for ANOVA with repeated measures for comparison between pre with each other period, *: statistically significant at $\mathrm{P} \leq 0.05$ )

\section{DISCUSSION}

Chemical composition and topographical aspects of the implant surface play a very important role during wound healing because they can determine which cell line will be stimulated and, consequently, express its genetically planned activity. It has been suggested that surface texture may also dictate the mechanism of osseointegration by influencing the stability of the fibrin scaffold, which is formed shortly after implantation (20).

Regarding the implant mobility, no clinical mobility was detected in any of the implants throughout the follow up period. This was confirmed by the radiographic evaluation that revealed intimate bone- implant contact and osseointegration in all implants. The absence of implant mobility is one of the most 
important criteria for implant success in accordance with Roos et al in 1997 (21).

As for the peri-implant probing depth, group A showed statistically significant lower probing depth values than the group B on the 4th month and statistically insignificant lower probing depth values 6 th and 9th months postoperatively. This agrees with clinical studies done by Ricci G et al in 2004 (22).

This study compared the marginal bone defect values between the two groups. At 4 months post- operatively the difference in marginal bone defect values between the two groups was found to be statistically insignificant but at 6 and 9 months the difference in marginal bone defect values was found to be statistically significant.

The overall increase in the marginal bone defect values throughout the follow up period may be due to adaptation of the crestal bone to the stress generated by the load, which causes resorption of the bone crest, and this agrees with Saturninoet al in 2014 (23). This agrees also with Lazzara R, Porter S in 2006 (24).

In our study the results revealed better osseointegration of laser treated implant. This was in accordance with the results of Faeda et al in 2009 (25), they concludes that the laser modified surface implants' physical and chemical properties increased the bone-implant interaction when compared to the machined surface implants.

Also, this is in agreement with Kang et al (26) in 2014, they compared the removal torque rate of both laser sintered and sand blasted acid etched implants inserted into both sides of the tibiae of 12 rabbits, after 6 weeks, the removal torque comparison showed that the removal torque of laser-treated implant surfaces was significantly higher than that of sand blasted acid etched implant surfaces

In contrast, Mangano et al (27) in 2010 demonstrated that the laser sintered titanium with compared to the acidetched titanium surfaces with stem cells from human dental pulp are capable to obtain osteoblast differentiation of stem cells of dental pulp, production of appreciable amounts of bone morphogenetic proteins as well as vascular endothelial growth factor and specific bone proteins. Therefore, a complete osteointegration was obtained in both surfaces.

Also Rong et al (28) in 2009, who evaluated early osseointegration of the laser-treated and acid-etched implant surface after the installation in rabbit tibias for 4 weeks. They observed that, no statistically significant differences existed among Direct Laser Metal Sintering (DLMS) group in removal torque values, compared to the acid etched group.).

\section{CONCLUSIONS}

The results of the present study showed that the use of both laser sintered implants and acid etched implants for replacement of maxillary premolars has significant success rates, with superior results of the laser sintered implants after an observation period of up to 9 months. Further researches are needed using a larger sample size and a histological comparison between both implant types to evaluate the effect of different manufacturing designs on osseointegration.

\section{CONFLICT OF INTEREST}

The authors declare that they have no conflicts of interest.

\section{REFERENCES}

1. Monjo M, Petzold C, Ramis J, Lyngstadaas S, Ellingsen J. In vitro osteogenic properties of two dental implant surfaces. Int J Biomater 2012; 14:112- 8 .

2. Mangano C, Piattelli A, Mangano F, Perrotti V, Iezzi G. Immediate loading of modified acid etched dental implantsin post-extraction sockets: a histological and histomorphometrical comparative study in nonhuman primate papio ursinus. Implant Dent 2009; 18: 142-50.

3. Sesma N, Pannuti C, Cardaropoli G. Retrospective clinical study of 988 dual acid-etched implants placed in grafted and native bone for single-tooth replacement. Int J Oral Maxillofac Implants 2012; 27:1243-8.

4. Choi J, Lee J, Jang J, Yeo I. Comparison between bioactive fluoride modified and bioinert anodically oxidized implant surfaces in early bone response using rabbit tibia model. Implant Dent 2012; 21: 124-8.

5. Degidi M, Nardi D, Piattelli A. 10-year follow-up of immediately loaded implants with Ti Unite porous anodized surface. Clin Implant Dent Relat Res 2012; 14: 828-38.

6. Mendes V, Moineddin R, Davies J. The effect of discrete calcium phosphate nanocrystals on bone-bonding to titanium surfaces. Biomaterials 2007; 28: 4748-55.

7. Elias C, Gravina P, Silva Filho C, Nascente P. Preparation of bioactive titanium surfaces via fluoride and fibronectin retention. Int J Biomater 2012; 29:179-87.

8. Rupp F, Gittens RL, Scheideler L. A review on the wettability of dental implant surfaces theoretical and experimental aspects. Acta Biomaterialia 2014; 10: 2894-906.

9. Larsson W, Thomsen P, Aronsson B, Rodahl M, Lausmaa J, Kasemo B, et al. Bone response to surface-modified titanium implants: studies on the early tissue response to implants with different surface characteristics. Int J Biomater 2013; 41:48292.

10. Mangano C, Perrotti V, Raspanti M, Mangano F, Luongo G, Piattelli A, et al. Human dental implants with a sandblasted, acid-etched surface retrieved after 5 and 10 years: a light and scanning electron microscopy evaluation of two cases. Int $\mathbf{J}$ Oral Maxillofac Implants 2013; 28: 917-20.

11. Mangano C, Mangano F, Shibli J , Ricci M , Sammons R, Figliuzzi M . Morse taper connection implants supporting "planned" maxillary and mandibular bar-retained overdentures: a 5-year prospective multicenter study. Clin Oral Implants Res 2011; 22: 1117-24.

12. Mullen L, Stamp R, Brooks W, Jones E, Sutcliffe C. Selective laser melting: a regular unit cell approach for the manufacture of porous, titanium, bone in-growth constructs, suitable for orthopedic applications. J Biomed Mater Res B App Biomater 2009; 89: 325-34.

13. Stamp R, Fox P, O’Neill W, Jones E, Sutcliffe C. The development of a scanning strategy for the manufacture of porous biomaterials by selective laser melting. J Mater Science Mater Med 2009; 20:1839-48.

14. Hollander D, Von Walter M, Wirtz T, Sellei R, SchmidtRohlfing B, Paar O, et al. Structural, mechanical and in vitro characterization of individually structuredTi- $6 \mathrm{Al}-4 \mathrm{~V}$ produced by direct laser forming. Biomaterials, 2006; 27: 955-63. 
15. Mangano C, Raspanti M, Traini T, Piattelli A, Sammons R. Stereo imaging and cytocompatibility of a model dental implant surface formed by direct laser fabrication. J Biomed Mater Res 2009; 88: 823-31.

16. Dabrowski B, Swieszkowski W, Godlinski D, Kurzydlowski K. Highly porous titanium scaffolds for orthopaedic applications. J Biomed Mater Res B, Appl Biomater 2010; 95: 53-61.

17. Glavind L, Loe $H$. Errors in clinical assessment of periodontal destruction. J periodontol 1967; 2:180-86.

18. Silness S, Loe H. Periodontal disease in pregnancy. Correlation between oral hygene and periodontal condition. Acta Odont Scand 1964; 22: 121-35.

19. Mckinney RV, Koth DL. The single-crystal sapphire endosteal dental implant: material characteristics and 18month experimental animal trials. J. Prosthet Dent 1982; 47(1): 69-84.

20. Gotfredsen K, Wennerberg A, Johansson C, Skovgaard LT, Hjørting-Hansen E. Anchorage of Ti02-blasted, HA-coated, and machined implants: an experimental study with rabbits. J Biomed Mater Res 1995; 29: 1223-31.

21. Roos J, Sennerby L, Lekholm U, Jemt T, Grondahl K, Albrektsson T. A qualitative and quantitative method for evaluating implant success: a 5-year retrospective analysis of the Branemark implant. Int J Oral Maxillofac Implants 1997; 12: 504-14.

22. Ricci G1, Aimetti M, Stablum W, Guasti A. Crestal bone resorption 5 years after implant loading: clinical and radiologic results with a 2-stage implant system. . Int J Oral Maxillofac Implants. 2004; 19(4): 597-602

23. Saturnino C, Viviane C, Thiago A, Benito A, Cristina D, Marcelo F, André G. Crestal Bone Resorption: An Assessment Cross-Section. Oral Health Dent Manag 2014; 13 (4): 967-70.

24. Lazzara RJ, Porter SS. Platform switching: A new concept in implant dentistry for controlling post restorative crestal bone levels. Int J Perio Rest Dent. 2006; 26: 9-17.

25. Faeda R, Tavares H, Sartori R, Guastaldi A, Marcantonio E. Evaluation of titanium implants with surface modification by laser beam. Biomechanical study in rabbit tibias. Braz Oral Res 2009; 23(2):137-43.

26. Kang N, Li L, Cho S. Comparison of removal torques between laser treated and SLA-treated implant surfaces in rabbit tibiae. J Adv Prosthod 2014; 6(4): 302-8.

27. Mangano C, De Rosa A, Desiderio V, d'Aquino R, Piattelli A, de Francesco F, et al. The osteoblastic differentiation of dental pulp stem cells and bone formation on different titanium surface textures. Biomaterials 2010; 31: 3543-51.

28. Rong M, Zhou L, Gou Z, Zhu A, Zhou D. The early osseointegration of the laser-treated and acid-etched dental implants surface: an experimental study in rabbits. J Mater Sci Mater Med 2009; 20: 1721-8.

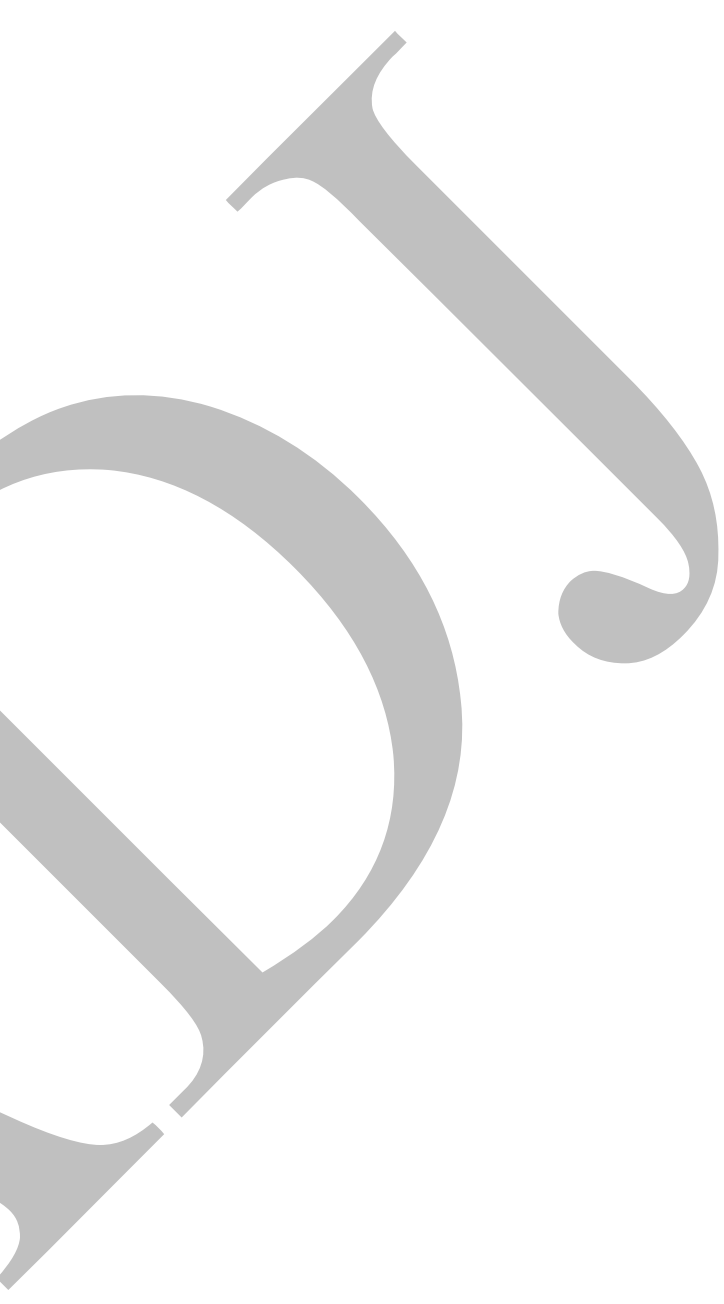
(n) 